\title{
A Positive Association Between Dietary Sodium Intake and Obesity and Central Obesity: Results from the National Health and Nutrition Examination Survey (NHANES) 1999-2006
}

\author{
Xi Zhang ${ }^{1 *}$, Jiawei Wang ${ }^{2 *}$, Jibin $\mathrm{Li}^{3}$, Yongfu Yu ${ }^{4}$, Yiqing Song 5
}

\section{Affiliations:}

1. Clinical Research Unit, Xin Hua Hospital Affiliated to Shanghai Jiao Tong University School of Medicine. Shanghai, China.

2. Douglas Mental Health University Institute, McGill University, Montreal, Quebec, Canada.

3. Department of Clinical Research, Sun Yat-sen University Cancer Center, State Key Laboratory of Oncology in South China, Collaborative Innovation Center for Cancer Medicine, Guangzhou, China.

4. Section for Epidemiology, Department of Clinical Epidemiology, Aarhus University Hospital, Aarhus, Denmark.

5. Department of Epidemiology, Richard M. Fairbanks School of Public Health, Indiana University. Indianapolis, IN, USA.

Short title: Dietary Sodium and Obesity

* These authors contributed equally.

Correspondence to Yiqing Song, MD, ScD, Department of Epidemiology, Richard M.

Fairbanks School of Public Health, Indiana University, 1050 Wishard Blvd., RG 5116, Indianapolis, IN 46202-2782.

Tel: 317-274-3833; Fax: 317-274-3443; E-mail: yiqsong@iu.edu

Word count: 4,224; Tables: 5; Figure: 4; Reference: 51.

This is the author's manuscript of the article published in final edited form as: Zhang, X., Wang, J., Li, J., Yu, Y., \& Song, Y. (2018). A positive association between dietary sodium intake and obesity and central obesity: results from the National Health and Nutrition Examination Survey 1999-2006. Nutrition Research, 55, 33-44. https://doi.org/10.1016/j.nutres.2018.04.008 


\section{List of Abbreviations}

NHANES: The National Health and Nutrition Examination Survey

NCHS: National Center for Health Statistics

CVD: Cardiovascular Disease

BMI: Body Mass Index

WC: Waist Circumference

BMD: Bone Mineral Density

ASM: Appendicular Skeletal Muscle Mass

ASMI: Appendicular Skeletal Muscle Index

WHtR: Waist-Height Ratio

DXA: Dual X-ray Absorptiometry

ORs: Odds Ratios

CIs: Confidence Intervals 


\section{ABSTRACT}

The link between sodium and obesity has been accumulated over years. However, there has been few data reported on such sodium-obesity association from the general U.S. population. This study is designed to assess the hypothesis that dietary sodium intake is independently and positively associated with obesity, central obesity, and measures of body composition among generally healthy U.S. adults. We analyzed data on 9,162 healthy participants aged 24- 48 (4,813 men and 4,349 women) with at least one valid diet recall from the 8-year NHANES survey (1999-2006). Measures of body composition, including fat mass, lean mass, and total fat percent, were determined by dual X-ray absorptiometry. We assessed the association between dietary sodium and obesity and measures of body composition by using multivariable logistic regression models. After adjustment for total energy intake and other pre-specified confounders, high sodium intake $(>2,300 \mathrm{mg} / \mathrm{d})$ was significantly associated with elevated risk of obesity and central obesity as compared to moderate sodium intake (1,500-2,300 mg/d). On average, each 1 $\mathrm{g} /$ day increment in dietary sodium intake resulted in a 15\% (OR: 1.15; 95\% CI: $1.00,1.33)$ increase in the risk of obesity and 24\% (OR: 1.24; 95\%: 1.11, 1.39) increase in the risk of central obesity. After stratification by gender and ethnicity, significant associations between sodium and obesity/abdominal obesity were apparent only among women and non-Hispanic whites. Additionally, all measures of body composition were positively associated with sodium consumption levels. We found that high sodium intake is independently associated with elevated risk of obesity and central obesity in the general U.S. adult population.

Keywords: dietary sodium, obesity, central obesity, body fat mass, body lean mass 


\section{Introduction}

Given the well-known robust link between obesity and increased risk of mortality and morbidity, especially its impact on cardiovascular disease (CVD), obesity is a major public health problem [1]. The recent National Health and Nutrition Examination Survey (NHANES, 2013-2014) reported that the age-adjusted prevalence of obesity (body mass index [BMI] $\geq 30$ $\mathrm{kg} / \mathrm{m}^{2}$ ) among the U.S. adults was 37.7\% [2]. Although the previous report from NHANES indicated that the prevalence of BMI-defined obesity in adults did not change significantly from 2003-2004 to 2011-2012 [3]. The age-adjusted prevalence of central obesity (waist circumference [4] $>102 \mathrm{~cm}$ for men and $>88 \mathrm{~cm}$ for women) increased from $46.4 \%(1999-2000)$ to $54.2 \%(2011-2012)[5]$ and continued to increase.

High sodium intake has been linked to a variety of increased risks of adverse health conditions such as hypertension [6, 7], CVD [7], and type 2 diabetes [8], although the underlying mechanism is still debatable [9]. In addition to all these traditionally recognized negative health effects of high sodium intake, obesity has recently gained much interest as another possible health-related outcome [10]. Several studies reported a significant association between sodium intake and obesity among adults [11-13]. Furthermore, recent evidence from nationally representative populations from South Korea, the UK, and Australia also identified a significant positive relationship between sodium intake and obesity among both youth and adults $[12,14-$ $16]$.

Although the mechanisms underlying the association between sodium intake and obesity have not been well established, the role of soft drink consumption has been explored [17]. This hypothesis contends that higher energy intake from sugar-sweetened beverages consumed to quench the thirst caused by high sodium intake would contribute to the obesity development [18], 
that is, salt intake is indirectly related to obesity through soft drink consumption, through its effect on fluid intake [19]. A controlled metabolic study in adults estimated that a decrease in salt from the current intake of approximately $10 \mathrm{~g} / \mathrm{d}$ to the WHO-recommended level of $5 \mathrm{~g} / \mathrm{d}$ would reduce total fluid consumption by $350 \mathrm{ml} /$ day [20]. It is known that a considerable proportion of fluid intake is in the form of soft drinks and that an increase in soft drink consumption is associated with an increase in BMI [21, 22]; therefore a reduction in salt intake could help reduce risk of obesity [23].

Obesity is a critical health concern in the U.S. general population [24]. For the last 20 years, the prevalence of obesity among U.S. adults has persisted at around $35 \%$, higher than that in either Canada or England [25, 26]. The 2015-2020 Dietary Guidelines for Americans from the Department of Health and Human Services and the United States Department of Agriculture recommend consuming less than $2300 \mathrm{mg} / \mathrm{d}$ dietary sodium for people aged $\geq 14$ years [27], while $89 \%$ of the U.S. adults consumed more than this recommended amount [28]. To date, few studies have examined the relationship between sodium intake and risk of obesity using data from the U.S. population. Therefore, we designed this study to determine whether dietary sodium is independently associated with overall and central obesity among the generally healthy adult population from NHANES 1999-2006.

\section{Methods and materials}

\subsection{Study Design and Population}

We used the eight-year combined data from four cycles of the NHANES survey, from 1999-2000 to 2005-2006. NHANES is based on a nationally representative, complex, multistage survey of the noninstitutionalized civilian population in the U.S. conducted by the National Center for Health Statistic of the Centers for Disease Control and Prevention. Data were 
collected during a home interview, and a health measurement was conducted in a Mobile Examination Center.

A total of 18,839 adults aged $\geq 18$ years completed at least one valid 24 -hour diet recall, among which 4,409 diet reports were from 1999-2000, 4,960 were from 2001-2002, 4,750 were from 2003-2004, and 4,720 were from 2005-2006. After excluding 9,000 patients with pregnancy, diabetes, CVD, hypertension, myocardial infarction, stroke, hyperlipidemia, cancer, liver diseases, or thyroid diseases, and 237 participants with implausible energy intakes (daily total energy intake $<500 \mathrm{kcal}$ or $>5,000 \mathrm{kcal})$, the remaining 9,162 $(4,813$ men and 4,349 women) and 9,306 (4,894 men and 4,412 women) generally healthy participants aged 24-48 years were included in the analyses for obesity and central obesity, respectively. (Fig. 1).

The National Center for Health Statistics (NCHS) Research Ethics Review Board (ERB) at the Centers for Disease Control and Prevention approved the overall design of NHANES [29]. All subjects provided written informed consent.

\subsection{Dietary Sodium}

Dietary sodium was assessed by 24-hour dietary recall interviews in the Mobile Examination Center or through telephone interview. For the surveys in 2003-2004 and 20052006, two 24-hour dietary recall interviews were conducted: the first by in-person in the Mobile Examination Center and the second by telephone 3-10 days later. For these two cycles, the mean value of dietary sodium calculated based on the two interviews was used for analysis. The 24hour recall data were collected using the U.S. Department of Agriculture's dietary data collection instrument, and the Food and Nutrient Database for Dietary Studies was used to translate typical portions of foods into gram weights of total nutrient intake. The dietary sodium data from 
NHANES were post-adjusted for salt usage at home for food preparation, based on the answers to the following questions: "How often is ordinary salt or seasoned salt added in cooking or preparing foods in your household? Is it never, rarely, occasionally, or very often?" If 'rarely' or 'never,' we removed all optional salt; if 'occasionally,' we removed half of the optional salt [30]. Dietary sodium density was calculated as total sodium $(\mathrm{mg})$ divided by total dietary energy (kcal).

\subsection{Obesity and Central Obesity}

Weight $(\mathrm{kg})$, height $(\mathrm{m})$, and WC $(\mathrm{cm})$ were measured in a mobile examination center using standardized techniques and equipment. BMI in $\mathrm{kg} / \mathrm{m}^{2}$ was calculated as weight divided by squared height. Waist-height ratio (WHtR) was calculated as waist circumference divided by height in centimeters. Obesity was defined as a BMI $\geq 30.0 \mathrm{~kg} / \mathrm{m}^{2}$. Central obesity was defined as a WC $>102 \mathrm{~cm}$ for men and $>88 \mathrm{~cm}$ for women [31].

\subsection{Measurements of Body Composition}

Dual energy X-ray absorptiometry (DXA) scans using a Hologic QDR 4500A fan-beam densitometer (Hologic, Inc., Bedford, Massachusetts) were administered to measure body composition. The DXA table upper-limit values for weight and height are $136.36 \mathrm{~kg}$ and 192.5 $\mathrm{cm}$, respectively. Therefore, individuals who self-reported a higher value for weight or height were excluded from DXA examination. Participants wore disposable paper gowns and removed all metal objects that might interfere with the scan image, such as jewelry, watches, hair ornaments, glasses, keys, and wallets. The scan for each survey participant was reviewed and analyzed by the University of California, San Francisco Department of Radiology using standard radiologic techniques and study-specific protocols developed for NHANES. Hologic Discovery 
software 12.1 was used to analyze the scans. Measures of fat mass (g), lean mass excluding bone mineral content $(\mathrm{g})$, and percent $(\%)$ body fat were obtained for the head, arms, legs, and trunk. AMS was calculated as the sum of the lean mass of both legs and arms. ASMI was defined as AMS divided by squared height $\left(\mathrm{kg} / \mathrm{m}^{2}\right)$.

\subsection{Confounders}

The variables adjusted in the model included age, sex, ethnicity (non-Hispanic white, non-Hispanic black, Mexican American, and others), education (less than high school, high school and college, and college graduate or above), smoking (smoked at least 100 cigarettes over lifetime), alcohol consumption (had at least 12 servings of alcohol/1yr), annual family income (< $\$ 25,000, \$ 25,000-45,000, \geq \$ 45,000)$, poverty income ratio $(\leq 1.85,1.86-3.5$, and $>3.5)$, physical activity (none, moderate, or vigorous), and sedentary time ( $<2$ hours, $2-4$ hours, or $>4$ hours), dietary potassium, total energy intake, blood pressure, fasting blood glucose, insulin, and creatinine levels. Information on demographic and socioeconomic factors was collected using a self-reported questionnaire. Similar to dietary sodium, dietary potassium and total energy intake were measured through the 24-hour dietary recall interview. Blood pressure was measured in sitting position by a trained physician using a mercury sphygmomanometer (Baumanometer; WA Baum Co. Inc., New York, USA). Each participant had up to four measurements [32]. The average values of four blood pressure measurements were used in the analyses.

Fasting blood samples with assured fasting status $\geq 8$ hours were stored at $-20^{\circ} \mathrm{C}$ conditions and shipped to the University of Missouri-Columbia for testing. Blood glucose levels were determined by oxygen rate. Insulin was measured using two-site enzyme radioimmunoassay. Serum creatinine was measured using the Jaffe method [32].

\subsection{Statistical Analyses}


Total dietary sodium intake was treated both as a continuous variable and as a categorical variable $(<1,500 \mathrm{mg} / \mathrm{d}, 1,500-2,300 \mathrm{mg} / \mathrm{d}$, and $>2,300 \mathrm{mg} / \mathrm{d})$ in the analyses [33]. Logistic regression models were adjusted for total energy intake to estimate the odds ratios (ORs) and $95 \%$ confidence intervals (CIs) of obesity and central obesity for categories of dietary sodium intake as compared to the reference group (1,500-2,300 $\mathrm{mg} / \mathrm{d})$. Weights accounting for the complex sampling design of the survey were applied in all analyses. Covariates such as age, sex, ethnicity, education, annual family income, cigarette smoking status, alcohol consumption, physical activity, sedentary time, and total energy intake were included in the models. Restricted cubic spline regression models were fitted by adjusting for total energy intake and the covariates mentioned above with four knots at $1.30,2.62,3.78$, and $6.19 \mathrm{mg} / \mathrm{d}$ to investigate a possible dose-response relationship between dietary sodium levels and risk of obesity and central obesity. Considering the influence of total energy intake, the dietary sodium density was calculated as total sodium divided by total energy intake. The associations between quartiles of dietary sodium density and obesity and central obesity were evaluated by using a similar logistic model adjusted for all the above-mentioned confounders except for total energy intake. The quartiles for dietary sodium density were $1.26,1.54,1.54$, and $1.86 \mathrm{mg} / \mathrm{kcal}$. Additionally, we used the residual method to calculate dietary sodium intake adjusted by total energy intake. We included residual sodium intake as a continuous independent variable or the tertile of residual sodium intake as a categorical independent variable in the multivariate logistic regression.

According to the body composition measures of DXA, we further quantified the association between dietary sodium and body composition, including total percent fat, body lean mass, body fat mass, appendicular skeletal muscle mass, and ASMI. We measured the body composition of 7,654 participants. Linear regression models were fitted to evaluate the 
association between dietary sodium levels and body composition.

The sensitivity analyses were restricted to participants with two 24-hour dietary recall interviews and those with vigorous physical activity.

A total of 9162 participants were included in this study, more than 3000 participants in each tertile, which achieved adequate statistical power required for this study. All statistical analyses were performed using SAS (version 9.4; SAS Institute) software. A $P$ value $<0.05$ for 2-tailed tests was considered statistically significant.

\section{Results}

The study comprised 4,813 men and 4,349 women aged 24-48 years (median: 35 years) were included in the study. Baseline characteristics are shown in table 1. The median daily sodium intake for all participants was $3.32 \mathrm{~g}$. Compared with the general recommendation of $2,300 \mathrm{mg} / \mathrm{d}, 76.4 \%$ of participants $(84.8 \%$ of women and $67.6 \%$ of men), had higher daily sodium intake. Participants who consumed high levels of sodium are more likely to be white ethnicity, be men, consume alcohol, take more energy, have more vigorous physical activity, and have large BMI and waist circumference.

\subsection{Dietary sodium and obesity}

Table 2 shows the relationship between total sodium intake and obesity. Nearly a quarter (23.4\%) of all participants was classified as obese. More than three quarters $(76.7 \%)$ of obese participants had a high-sodium diet, while only $16.1 \%$ had sodium intake within the general recommendation range. Compared with participants reporting recommended levels of sodium intake, those with high-sodium diets were more likely to be obese; the OR of obesity was 1.55 (95\% CI: 1.09, 2.20) after adjustment for potential confounders including age, gender, ethnicity, 
total energy intake, smoking, alcohol consumption, physical activity, sedentary time, education, and annual family income. The low-sodium diet (dietary sodium levels $<1,500 \mathrm{mg} / \mathrm{d}$ ) was not significantly associated with the risk of obesity (OR of $0.95 ; 95 \% \mathrm{CI}: 0.48,1.89$ ). As sodium consumption increased, so did the risk of obesity $(P$-trend $<0.01)$, with each $1 \mathrm{~g}$ increase in sodium intake associated with a 15\% (OR: 1.15; 95\% CI: 1.00, 1.33) elevation in obesity risk. The cubic spline model indicated a significant elevation in obesity risk once total dietary sodium exceeded 2,300 mg/d ( $P$ for nonlinear trend $=0.001$, Fig. 2).

A significant association between dietary sodium and obesity was observed in women but

not in men. After adjustment for the confounders mentioned above except sex, the OR of obesity for per $1 \mathrm{~g}$ increment in sodium intake was 1.31 (95\% CI: 1.02, 1.69) among women and 1.02 $(0.87,1.21)$ among men. Analysis stratified by ethnicity found that this association was observed only among non-Hispanic whites and Mexican Americans. Among Mexican Americans, participants with a high-sodium $\operatorname{diet}(>2,300 \mathrm{mg} / \mathrm{d})$ had nearly threefold greater risk (OR: 2.83; $95 \%$ CI: $1.30,6.16)$ of obesity compared to those with recommended sodium intake $(1,500-2,300$ $\mathrm{mg} / \mathrm{d})$. Each $1 \mathrm{~g}$ increase in dietary sodium was associated with $21 \%$ (OR: $1.21 ; 95 \% \mathrm{CI}: 0.95$, 1.54) increase in obesity risk. For non-Hispanic whites, ORs for obesity per gram of sodium increment was 1.23 (95\% CI: 1.02, 1.49) in the adjusted model. However, this sodium-obesity association was not detected among other ethnicities.

\subsection{Dietary sodium and central obesity}

Among 9,306 participants, 3,274 (women: 60.2\%, men: 39.8\%) achieved the diagnostic criteria for central obesity. Among those with central obesity, 75.6\% had a high-sodium diet, while only $16.8 \%$ had sodium intake within the general recommendation range. Similar to the results for obesity, a positive association between dietary sodium and central obesity was noted 
among all participants (Table 3). The risk of central obesity was 1.78 (95\% CI: 1.29, 2.45) for participants with high-sodium diets and 1.28 (95\% CI: 0.72, 2.29) for those with low-sodium diets, compared with those with normal-sodium diets. As sodium consumption increased, risk of central obesity was significantly elevated $(P$-trend $=0.003)$; each $1 \mathrm{~g}$ increment in sodium intake resulted in $24 \%$ (OR: 1.24; $95 \%$ CI: 1.11, 1.39) elevation of central obesity risk. The spline model also showed a nonlinear relationship between dietary sodium and central obesity (Fig. 3).

For women, the risk of central obesity in the high-sodium diet group was 75\% (OR: 1.75; $95 \%$ CI: 1.14, 2.70) higher than that in the normal-sodium diet group, but there is no significant elevation for the risk among men with a high-sodium diet. Stratified analysis by ethnicity indicated that high sodium intake $(>2,300 \mathrm{mg} / \mathrm{d})$ was positively associated with the risk of central obesity among non-Hispanic whites, (OR: 2.31; 95\% CI: 1.36, 3.91; reference group: 1,500-2,300 mg/d). Each $1 \mathrm{~g}$ increment in dietary sodium intake was associated with a 34\% (OR: 1.34; $95 \%$ CI: $1.14,1.58)$ increased risk of central obesity. However, this sodium-obesity association was not detected among other ethnicities, including non-Hispanic blacks and Mexican Americans. Consistent results were found when we included the residual sodium intake in the logistic regression models, either when it was treated as a continuous variable or a categorical variable (Table 4).

\subsection{Dietary sodium density and obesity}

No significant association between dietary sodium density and obesity was found (Fig. 4). As dietary sodium density increased from the lowest quartile $(1.08 \mathrm{mg} / \mathrm{kcal})$ to the highest quartile $(2.13 \mathrm{mg} / \mathrm{kcal})$, central obesity risk increased from 1 (referent) to $1.18(0.82,1.69), 1.29$ $(0.76,2.19)$, and $1.46(0.97,2.19)$; the linear trend of this association was marginally significant $(P$-trend $=0.08)$. 


\subsection{Dietary sodium and body composition}

Nearly $82 \%$ of participants had complete DXA measurements. All variables of body composition (weight, waist, BMI, total percent fat, body lean mass, body fat mass, appendicular skeletal muscle mass, and ASMI) were positively associated with sodium intake and dietary sodium density (Table 5) after adjustment for all potential confounders. Each $1 \mathrm{~g}$ increment in daily sodium intake was linked to $1.38 \mathrm{~kg}(95 \% \mathrm{CI}: 0.14,2.62 \mathrm{~kg})$ increase in weight, $0.50 \mathrm{~kg} / \mathrm{m}^{2}$ (95\% CI: $\left.0.09,0.91 \mathrm{~kg} / \mathrm{m}^{2}\right)$ increase in BMI, $1.07 \mathrm{~cm}(0.28,1.85 \mathrm{~cm})$ increase in waist circumference, $0.44 \%(95 \% \mathrm{CI}: 0.07,0.81)$ elevation in total percent fat, and $0.79 \mathrm{~kg}(95 \% \mathrm{CI}$ : $0.17,1.40 \mathrm{~kg}$ ) elevation in body fat mass. Similar results were found for the association between dietary sodium density and body composition, and results changed only slightly when we substituted residual sodium intake for total sodium intake (Table 4).

\subsection{Sensitivity analyses}

When analyses were restricted to participants with two 24-hour dietary recall interviews, the associations between sodium and obesity and central obesity became stronger: the OR was 1.56 (95\% CI: $1.15,2.11)$ for obesity and $1.41(95 \%$ CI: $1.13,1.75)$ for central obesity. Analyses among participants with vigorous physical activity also indicated stronger associations between sodium and obesity and central obesity. After including the patients with a history of hypertension, the ORs between dietary sodium intake and obesity and central obesity did not change significantly, and they were $1.22(1.08,1.37)$ and $1.19(1.08,1.32)$, respectively.

\section{Discussion}

Using the data from four waves of NHANES (1999-2006), we found that the median daily sodium intake for the U.S. general adult population was $3.32 \mathrm{~g}$ and that fewer than $30 \%$ of adults 
met the recommended levels of sodium intake $(<2,300 \mathrm{mg} / \mathrm{d})$; compared with adults who met the recommended levels, participants who had higher dietary sodium intake than the recommended levels, had a high risk of obesity and central obesity. Each $1 \mathrm{~g}$ increment in sodium intake led to $15 \%$ and $24 \%$ increases in the risks of obesity and central obesity, respectively. Additionally, our results also revealed that increases in daily sodium intake or dietary sodium density were linked with significant elevations in measures of body composition, such as body fat mass, body lean mass, and total percent fat in the U.S. general population.

Emerging evidence has suggested that high-salt diets are both directly and indirectly linked to weight gain. Several possible mechanisms have been postulated to explain this association. Foods high in sodium are generally high in energy, such as fatty foods $[34,35]$. Additionally, these types of foods produce a subsequent rise in overeating behaviors, leading to weight gain [36]. Another suggestion is that intake of soft drinks is increased by higher sodium intake $[18,37][19]$. Considering all these potential reasons, energy intake may be a mediator on the causal pathway between sodium intake and obesity. While our study found that sodium intake was positively associated with obesity risk, independent of total energy intake, similar results were obtained from nationally representative samples in South Korea $[12,14]$ and the UK [16]. For both Korean and the UK adults, high sodium intake was associated with a 20\% increased risk of obesity; for children, high-sodium intake was associated with a $30 \%$ increased risk of obesity in the UK subjects and an $80 \%$ increased obesity risk in South Korean subjects. Moreover, a study among healthy children and adolescents showed that high intake of salty foods was associated with higher body weight, independent of soft drink consumption [38]. All these pieces of evidence support the hypothesis that there might be a direct effect of high sodium intake on weight gain, in addition to the mediated effects through energy intake. Although the 
mechanisms underlying such a relationship are not completely understood, several animal studies imply that high sodium intake may affect the insulin and glucose metabolism, increasing leptin production or secretion and enhancing leptin resistance, which further causes energy dysregulation, accumulation of adipose tissue mass, and finally development of obesity [39][16, $40]$.

As we know, abdominal obesity is an index of non-balanced distribution of body fat, which is associated with elevated risk of cardiovascular diseases, metabolic diseases, and also total mortality [41-44]. Therefore, in this study, we also examined the relationship between sodium intake and central obesity as measured by waist circumstance. Consistent with the results of obesity measured by BMI, high levels of sodium intake were linked with a high risk of central obesity. The probability of abdominal obesity was $78 \%$ higher among participants with daily sodium intake $>2,300 \mathrm{mg}$ compared to those with recommended levels $1,500-2,300 \mathrm{mg} / \mathrm{d}$; and this probability was $55 \%$ for overall obesity. This significant association was further supported by our DXA data, which showed that high sodium intake was positively linked with high measures of body composition, such as total percent fat, body fat mass, and lean mass after controlling for total energy intake. After separation by gender, for both obesity and abdominal obesity, the association was significant only in women but not in men. Several studies have evaluated possible gender differences in the sodium-obesity association $[45,46]$. However, most such studies indicated a consistent association for men and women. Only one study, including 2,163 Korean children (1,106 boys and 1,057 girls) aged 8-9 years, evaluated the association between 11 salt-sensitive genes and obesity risk and found a gender difference in the effect of the GRK4 A486V polymorphism on the risk of obesity. In this study, boys who carried mutant homozygotes showed a high risk of obesity, while girls with high risk of obesity were carrying 
heterozygotes rather than mutants [9]. Moreover, physiological research has revealed that this gender difference might be attributable to the effect of increased renal sodium resorption and water retention produced by female hormones, such as estrogen and progesterone [47]. These findings warrant future research into the gender discrepancy in the sodium-obesity association.

It is well known that the U.S. obesity epidemic is disproportionately distributed among different racial and ethnic groups [24, 48, 49]. According to data from NHANES 2009-2010, approximately $50 \%$ of non-Hispanic blacks and $40 \%$ of Mexican Americans are obese, compared with only $34 \%$ of non-Hispanic whites [24]. The NHANES 1999-2004 used in this study oversampled non-Hispanic blacks, Mexican Americans, and low-income whites, which enabled us to explore racial heterogeneity in the sodium-obesity association. Our data suggest a racial differentiation in this association. Non-Hispanic whites were more sensitive to high sodium intake than were non-Hispanic blacks or other racial groups. Each $1 \mathrm{~g}$ increment in daily sodium intake led to a $23 \%$ increase in the risk of obesity and a $34 \%$ increase in the risk of abdominal obesity among non-Hispanic whites. Similar to Mexican Americans, a threefold higher risk of obesity was found in subjects with high daily sodium intake. However, no significant association was observed in non-Hispanic blacks or other racial groups. Although the most common explanation for the racial disparity in obesity involves socioeconomic factors and lifestyle determinants, recent evidence indicates that genetic differences may also contribute to such disparities [50]. In addition, there is evidence from studies on hypertension implicating racial disparities in salt-sensitivity in response to changes in dietary sodium intake [51]. However, such speculation regarding whether similar racial disparities exist in the sodium-obesity association needs to be confirmed in further specific studies.

Our study has several strengths. This study included eight years of data from four cycles of 
the NHANES survey, from 1999-2000 to 2005-2006. The NHANES population is the nationally representative noninstitutionalized civilian population in the U.S.; therefore, the results are generalizable to the population of the U.S. adults. Also, the NHANES includes different racial populations, especially for the 1999-2004 survey, which oversampled non-Hispanic blacks, Mexican Americans, and low-income whites, which provides a sufficient sample to explore racial disparities in the sodium-obesity association. In addition, NHANES 1999-2004 assessed body composition by whole body DXA, the most accurate way of assessing full body composition, which may be a strong predictor of obesity complications. We found that dietary sodium intake was positively associated with total percent of fat and body fat mass. To exclude the influence of total energy intake, we included it as an independent variable or as dietary sodium density in our models. Moreover, consistent results were obtained using the residual method to calculate the residual sodium intake, adjusted for total energy. Further, to avoid the influence of participants reporting implausible energy intakes, we excluded those with daily total energy intake $<500 \mathrm{kcal}$ or $>5,000 \mathrm{kcal}$.

However, there are also several limitations of this study. First, it is based on cross-sectional surveys, which are difficult to directly interpret as evidence of a causal relationship. Second, dietary sodium consumption was measured by 24-hour dietary recall, which might underestimate sodium intake and be less accurate than a 24-hour urine sodium; and 24-hour urine was collected only in a small subpopulation in the NHANES. Our sensitivity analysis restricted to participants with two 24-hour dietary recall interviews also showed stronger associations between sodium and obesity and central obesity. Third, NHANES does not include information on soft drink consumption. However, we controlled for total energy intake in the analysis, which was estimated from all foods and beverages consumed during the 24-hour period prior to the 
interview. Finally, although we adjusted for a comprehensive set of covariates in our multivariable models, we could not account for other unobserved confounders, including dietary and genetic differences.

In conclusion, we found that high sodium intake was associated with high prevalence of obesity and central obesity as well as high levels of body fats among a general population of U.S. adults. Our study suggests that adhering to the recommended sodium intake could have important public health implications. Additionally, gender and racial variations in the sodiumobesity association illustrate that salt-sensitivity may play a role not only in the sodiumhypertension association but also in the association between sodium and obesity. 


\section{Acknowledgments}

The authors declare no conflict of interest. The project described was supported by the Indiana University Health - Indiana University School of Medicine Strategic Research Initiative (YS). YS and XZ designed and conducted the research; XZ analyzed data and had primary responsibility for the final content of the manuscript; JWW designed study, analyzed data, and conducted the research; and all authors took part in writing the manuscript, and read and approved the final manuscript. We gratefully acknowledged Julian Little (Canada Research Chair in Human Genome Epidemiology, School of Epidemiology, Public Health and Preventive Medicine, University of Ottawa, Canada) for providing helpful comments. 


\section{REFERENCES}

[1] Ortega FB, Lavie CJ, Blair SN. Obesity and Cardiovascular Disease. Circ Res 2016; 118: 1752-70.

[2] Flegal KM, Kruszon-Moran D, Carroll MD, Fryar CD, Ogden CL. Trends in Obesity Among Adults in the United States, 2005 to 2014. JAMA 2016; 315: 2284-91.

[3] Ogden CL, Carroll MD, Kit BK, Flegal KM. Prevalence of childhood and adult obesity in the United States, 2011-2012. JAMA 2014; 311: 806-14.

[4] Zwolinska-Wcislo M, Piatek-Guziewicz A, Paśko P, Zagrodzki P, Krośniak M, Przybylska-Feluś M, et al. The selected parameters of oxidative stress, antioxidant capacity and inflammatory mediators in treated and untreated adult patients with coeliac disease-a preliminary report. United European Gastroenterology Journal 2015; 3: A500-A01.

[5] Ford ES, Maynard LM, Li C. Trends in mean waist circumference and abdominal obesity among US adults, 1999-2012. JAMA 2014; 312: 1151-3.

[6] He FJ, Li J, Macgregor GA. Effect of longer term modest salt reduction on blood pressure: Cochrane systematic review and meta-analysis of randomised trials. BMJ 2013; 346: f1325.

[7] Vollmer WM, Sacks FM, Ard J, Appel LJ, Bray GA, Simons-Morton DG, et al. Effects of diet and sodium intake on blood pressure: subgroup analysis of the DASH-sodium trial. Ann Intern Med 2001; 135: 1019-28.

[8] $\mathrm{Hu}$ G, Jousilahti P, Peltonen M, Lindstrom J, Tuomilehto J. Urinary sodium and potassium excretion and the risk of type 2 diabetes: a prospective study in Finland. Diabetologia 2005; 48: 1477-83.

[9] Lee M, Kim MK, Kim SM, Park H, Park CG, Park HK. Gender-based differences on the association between salt-sensitive genes and obesity in Korean children aged between 8 and 9 years. PLoS One 2015; 10: e0120111.

[10] Populations CotCoSRi, Sodium Intake in Populations: Assessment of Evidence, National Academy of Sciences, Washington, DC, 2013.

[11] Song HJ, Cho YG, Lee HJ. Dietary sodium intake and prevalence of overweight in adults. Metabolism 2013; 62: 703-8.

[12] Yoon YS, Oh SW. Sodium density and obesity; the Korea National Health and Nutrition Examination Survey 2007-2010. Eur J Clin Nutr 2013; 67: 141-6.

[13] Larsen SC, Angquist L, Sorensen TI, Heitmann BL. 24h urinary sodium excretion and subsequent change in weight, waist circumference and body composition. PLoS One 2013; 8: e69689.

[14] Lee SK, Kim MK. Relationship of sodium intake with obesity among Korean children and adolescents: Korea National Health and Nutrition Examination Survey. Br J Nutr 2016; 115: 834-41. 
[15] Grimes CA, Riddell LJ, Campbell KJ, He FJ, Nowson CA. 24-h urinary sodium excretion is associated with obesity in a cross-sectional sample of Australian schoolchildren. Br J Nutr 2016; 115: 1071-9.

[16] Ma Y, He FJ, MacGregor GA. High salt intake: independent risk factor for obesity? Hypertension 2015; 66: 843-9.

[17] He FJ, Marrero NM, MacGregor GA. Salt Intake Is Related to Soft Drink Consumption in Children and Adolescents: A Link to Obesity? Hypertension 2008; 51: 629-34.

[18] Grimes CA, Riddell LJ, Campbell KJ, Nowson CA. Dietary salt intake, sugar-sweetened beverage consumption, and obesity risk. Pediatrics 2013; 131: 14-21.

[19] He FJ, Marrero NM, MacGregor GA. Salt intake is related to soft drink consumption in children and adolescents: a link to obesity? Hypertension 2008; 51: 629-34.

[20] He FJ, Markandu ND, Sagnella GA, MacGregor GA. Effect of salt intake on renal excretion of water in humans. Hypertension 2001; 38: 317-20.

[21] Vartanian LR, Schwartz MB, Brownell KD. Effects of soft drink consumption on nutrition and health: a systematic review and meta-analysis. Am J Public Health 2007; 97: 667-75.

[22] Wang J, Shang L, Light K, O'Loughlin J, Paradis G, Gray-Donald K. Associations between added sugar (solid vs. liquid) intakes, diet quality and adiposity indicators in Canadian children. Applied Physiology, Nutrition, and Metabolism 2015.

[23] He FJ, MacGregor GA. A comprehensive review on salt and health and current experience of worldwide salt reduction programmes. J Hum Hypertens 2009; 23: 363-84.

[24] Flegal KM, Carroll MD, Kit BK, Ogden CL. Prevalence of obesity and trends in the distribution of body mass index among US adults, 1999-2010. JAMA 2012; 307: 491-7.

[25] Shields M, Carroll MD, Ogden CL. Adult obesity prevalence in Canada and the United States. NCHS Data Brief 2011; 1-8.

[26] National Statistics Statistics on Obesity PAaD-E, 2016 . National Health Service Information Center http://content.digital.nhs.uk/catalogue/PUB20562/obes-phys-acti-diet-eng-2016-rep.pdf. Accessed October, 2016.

[27] Millen BE, Abrams S, Adams-Campbell L, Anderson CA, Brenna JT, Campbell WW, et al. The 2015 Dietary Guidelines Advisory Committee Scientific Report: Development and Major Conclusions. Advances in nutrition (Bethesda, Md.) 2016; 7: 438-44.

[28] Jackson SL, King SM, Zhao L, Cogswell ME. Prevalence of Excess Sodium Intake in the United States - NHANES, 2009-2012. MMWR Morb Mortal Wkly Rep 2016; 64: 1393-7. 
[29] Li XT, Yu PF, Gao Y, Guo WH, Wang J, Liu X, et al. Association between Plasma Metal Levels and Diabetes Risk: a Case-control Study in China. Biomedical and environmental sciences : BES 2017; 30: 482-91.

[30] Rhonda S. Sebastian CWE, Lois C. Steinfeldt, Joseph D. Goldman, and Alanna J. Moshfegh. Discontinuation of Data Processing Step: Salt Adjustment on Designated Foods Likely To Be Home Prepared. U.S. Dept. of Agriculture, Agricultural Research Service 2012.

[31] Batsis JA, Nieto-Martinez RE, Lopez-Jimenez F. Metabolic syndrome: from global epidemiology to individualized medicine. Clin Pharmacol Ther 2007; 82: 509-24.

[32] National Health and Nutrition Examination Survey: Questionnaires d, and related documentation. Available at: http://www.cdc.gov/nchs/nhanes/nhanes_questionnaires.htm.

[33] Strom BL YA, Oria M, eds. Committee on the Consequences of Sodium Reduction in Populations, Food and Nutrition Board, Board on Population Health and Public Health Practice, Institute of Medicine. Sodium Intake in Populations: Assessment of Evidence. Washington, DC: National Academies Press; August 2013.

[34] Bolhuis DP, Lakemond CM, de Wijk RA, Luning PA, de Graaf C. Effect of salt intensity in soup on ad libitum intake and on subsequent food choice. Appetite 2012; 58: 48-55.

[35] Mejean C, Deglaire A, Kesse-Guyot E, Hercberg S, Schlich P, Castetbon K. Association between intake of nutrients and food groups and liking for fat (The Nutrinet-Sante Study). Appetite 2014; 78: 147-55.

[36] Keskitalo K, Tuorila H, Spector TD, Cherkas LF, Knaapila A, Kaprio J, et al. The Three-Factor Eating Questionnaire, body mass index, and responses to sweet and salty fatty foods: a twin study of genetic and environmental associations. Am J Clin Nutr 2008; 88: 263-71.

[37] Grimes CA, Wright JD, Liu K, Nowson CA, Loria CM. Dietary sodium intake is associated with total fluid and sugar-sweetened beverage consumption in US children and adolescents aged 2-18 y: NHANES 2005-2008. Am J Clin Nutr 2013; 98: 189-96.

[38] Libuda L, Kersting M, Alexy U. Consumption of dietary salt measured by urinary sodium excretion and its association with body weight status in healthy children and adolescents. Public Health Nutr 2012; 15: 433-41.

[39] Baudrand R, Lian CG, Lian BQ, Ricchiuti V, Yao TM, Li J, et al. Long-term dietary sodium restriction increases adiponectin expression and ameliorates the proinflammatory adipokine profile in obesity. Nutr Metab Cardiovasc Dis 2014; 24: 34-41.

[40] Lanaspa MA, Kuwabara M, Andres-Hernando A, Li N, Cicerchi C, Jensen T, et al. High salt intake causes leptin resistance and obesity in mice by stimulating endogenous fructose production and 
metabolism. Proceedings of the National Academy of Sciences of the United States of America 2018; 115: 3138-43.

[41] Yusuf S, Hawken S, Ounpuu S, Dans T, Avezum A, Lanas F, et al. Effect of potentially modifiable risk factors associated with myocardial infarction in 52 countries (the INTERHEART study): casecontrol study. Lancet 2004; 364: 937-52.

[42] Bozkurt NC, Beysel S, Karbek B, Unsal IO, Cakir E, Delibasi T. Visceral Obesity Mediates the Association Between Metabolic Syndrome and Obstructive Sleep Apnea Syndrome. Metab Syndr Relat Disord 2016; 14: 217-21.

[43] An KO, Kim J. Association of Sarcopenia and Obesity With Multimorbidity in Korean Adults: A Nationwide Cross-Sectional Study. J Am Med Dir Assoc 2016; 17: 960 e1-7.

[44] Sahakyan KR, Somers VK, Rodriguez-Escudero JP, Hodge DO, Carter RE, Sochor O, et al. NormalWeight Central Obesity: Implications for Total and Cardiovascular Mortality. Ann Intern Med 2015; 163: 827-35.

[45] Yi SS, Kansagra SM. Associations of sodium intake with obesity, body mass index, waist circumference, and weight. Am J Prev Med 2014; 46: e53-5.

[46] Huh JH, Lim JS, Lee MY, Chung CH, Shin JY. Gender-specific association between urinary sodium excretion and body composition: Analysis of the 2008-2010 Korean National Health and Nutrition Examination Surveys. Metabolism 2015; 64: 837-44.

[47] He J, Gu D, Chen J, Jaquish CE, Rao DC, Hixson JE, et al. Gender difference in blood pressure responses to dietary sodium intervention in the GenSalt study. J Hypertens 2009; 27: 48-54.

[48] Wang Y, Beydoun MA, Liang L, Caballero B, Kumanyika SK. Will all Americans become overweight or obese? estimating the progression and cost of the US obesity epidemic. Obesity (Silver Spring) 2008; 16: 2323-30.

[49] Ogden CL, Carroll MD, Curtin LR, McDowell MA, Tabak CJ, Flegal KM. Prevalence of overweight and obesity in the United States, 1999-2004. JAMA 2006; 295: 1549-55.

[50] Fesinmeyer MD, North KE, Ritchie MD, Lim U, Franceschini N, Wilkens LR, et al. Genetic risk factors for BMI and obesity in an ethnically diverse population: results from the population architecture using genomics and epidemiology (PAGE) study. Obesity (Silver Spring) 2013; 21: 835-46.

[51] Richardson SI, Freedman BI, Ellison DH, Rodriguez CJ. Salt sensitivity: a review with a focus on non-Hispanic blacks and Hispanics. J Am Soc Hypertens 2013; 7: 170-9. 


\section{Figures Legends}

Figure 1. Flow chart for participants selection

Figure 2. Adjusted odds ratios of obesity (defined as BMI $\geq 30.0 \mathrm{~kg} / \mathrm{m}^{2}$ ) in the U.S. general adults (NHANES 1999-2006). The solid curve represents for multivariate-adjusted odds ratios calculated by restricted cubic splines with knots at dietary sodium levels of $1.30,2.62,3.78$, and $6.19 \mathrm{~g} / \mathrm{d}$. The reference value $(\mathrm{OR}=1)$ was set at sodium levels of 2,300 $\mathrm{mg} / \mathrm{d}$. Odds ratios were estimated by using weighted logistic regression model adjusted for age, sex, ethnicity, education, annual family income, cigarette smoking status, alcohol consumption, physical activity, sedentary time, and total energy intake.

Figure 3. Adjusted odds ratios of central obesity (defined as waist circumference $>88 \mathrm{~cm}$ for women and $>102 \mathrm{~cm}$ for men) in the U.S. general adults (NHANES 1999-2006). The solid curve represents for multivariate-adjusted odds ratios calculated by restricted cubic splines with knots at dietary sodium levels of $1.30,2.62,3.78$, and $6.19 \mathrm{~g} / \mathrm{d}$. The reference value $(\mathrm{OR}=1)$ was set at sodium levels of 2,300 mg/d. Odds ratios were estimated by using weighted logistic regression model adjusted for age, sex, ethnicity, education, annual family income, cigarette smoking status, alcohol consumption, physical activity, sedentary time, and total energy intake. Figure 4. Adjusted odds ratios of obesity and central obesity according to the quartiles for dietary sodium density (daily total dietary sodium/total energy intake, $\mathrm{mg} / \mathrm{kcal}$ ). The quartile range of dietary sodium density: quartile $1(\mathrm{Q} 1):<1.26 \mathrm{mg} / \mathrm{kcal}$, quartile $2(\mathrm{Q} 2):<1.26-1.53$ $\mathrm{mg} / \mathrm{kcal}$, quartile 3(Q3): 1.54-1.85 mg/kcal, quartile 4 (Q4): $\geq 1.86 \mathrm{mg} / \mathrm{kcal}$. 
Table 1. Demographic characteristics of the participants according to the categories of dietary sodium intake

\begin{tabular}{|c|c|c|c|c|}
\hline Variables & $\begin{array}{c}<1500 \mathrm{mg} / \mathrm{d} \\
\text { median }=1171 \\
\mathrm{n}=829\end{array}$ & $\begin{array}{c}1500-2300 \mathrm{mg} / \mathrm{d} \\
\text { median }=1948 \\
n=1714\end{array}$ & $\begin{array}{c}>2300 \mathrm{mg} / \mathrm{d} \\
\text { median }=3771 \\
\mathrm{n}=6763\end{array}$ & $P$-values \\
\hline Age, $y$ & $34(24,46)$ & $37(26,48)$ & $34(25,45)$ & $<0.0001$ \\
\hline Male sex & $322(35.9)$ & 635 (31.9) & $3937(56.9)$ & $<0.0001$ \\
\hline Ethnicity & & & & $<0.0001$ \\
\hline Non-Hispanic White & $221(52.2)$ & $639(64.6)$ & $2971(69.6)$ & \\
\hline Non-Hispanic Black & $205(16.3)$ & $393(12.2)$ & $1452(10.2)$ & \\
\hline Mexican American & $319(15.0)$ & $531(11.1)$ & $1763(9.3)$ & \\
\hline All Others & $84(16.6)$ & $151(12.2)$ & $577(10.9)$ & \\
\hline Current smoker & $298(48.3)$ & $578(44.0)$ & $2498(46.4)$ & 0.31 \\
\hline Current drinker & $200(57.4)$ & $372(55.7)$ & $1394(68.4)$ & 0.0002 \\
\hline Highest education & & & & $<0.0001$ \\
\hline Less than high school & $370(33.3)$ & $562(21.3)$ & $1824(17.2)$ & \\
\hline High school and college & $336(50.2)$ & $778(52.7)$ & $3421(56.2)$ & \\
\hline College graduate or above & $84(16.5)$ & $286(26.0)$ & $1258(26.7)$ & \\
\hline Family income & & & & $<0.0001$ \\
\hline$<\$ 25,000$ & $416(44.3)$ & $717(34.4)$ & $2535(29.8)$ & \\
\hline$\$ 25,000-45,000$ & $159(23.2)$ & $348(22.2)$ & $1392(21.2)$ & \\
\hline$\geq \$ 45,000$ & $191(32.5)$ & $542(43.5)$ & $2454(49.1)$ & \\
\hline Poverty income ratio & & & & $<0.0001$ \\
\hline$\leq 1.85$ & $412(45.9)$ & $762(37.3)$ & $2720(31.2)$ & \\
\hline $1.86-3.5$ & $185(26.7)$ & $375(24.8)$ & $1572(26.0)$ & \\
\hline$>3.5$ & $147(27.4)$ & $425(37.9)$ & $1994(42.9)$ & \\
\hline Physical activity & & & & 0.20 \\
\hline Moderate & $204(47.0)$ & $473(48.5)$ & $2036(47.9)$ & \\
\hline Vigorous & $241(53.0)$ & $533(51.5)$ & $2498(52.1)$ & \\
\hline Sedentary time & & & & 0.01 \\
\hline$<2$ hours & $275(35.1)$ & $580(36.2)$ & $2117(33.4)$ & \\
\hline 2-4 hours & $420(49.6)$ & $871(50.3)$ & $3700(55.0)$ & \\
\hline$>4$ hours & $134(15.3)$ & $263(13.6)$ & $946(11.6)$ & \\
\hline Total energy intake, $\mathrm{kcal} / \mathrm{d}$ & $1219.6(26.3)$ & $1556.8(17.3)$ & $2522.3(12.5)$ & $<0.0001$ \\
\hline Dietary sodium density, mg/kcal & $1.03(0.02)$ & $1.35(0.01)$ & $1.69(0.008)$ & $<0.0001$ \\
\hline Indexed daily sodium, $\mathrm{mg} / \mathrm{kg} / \mathrm{m}^{2}$ & $43.2(0.9)$ & $77.2(0.5)$ & $159.5(0.96)$ & $<0.0001$ \\
\hline Dietary potassium, $\mathrm{g} / \mathrm{d}$ & $1.50(0.03)$ & $2.03(0.03)$ & $2.94(0.02)$ & $<0.0001$ \\
\hline \multicolumn{5}{|l|}{ Blood pressure, mmHg } \\
\hline Systolic BP & $117.8(0.7)$ & $117.0(0.6)$ & $117.2(0.3)$ & 0.78 \\
\hline Diastolic BP & $69.9(0.6)$ & $69.7(0.4)$ & $70.5(0.2)$ & 0.01 \\
\hline Glucose, mg/dL & $95.4(0.8)$ & $94.7(0.7)$ & $94.9(0.5)$ & 0.91 \\
\hline Insulin, uU/mL & $10.6(0.5)$ & $9.58(0.3)$ & $10.4(0.2)$ & 0.54 \\
\hline Creatinine, $\mathrm{mg} / \mathrm{dL}$ & $0.75(0.01)$ & $0.78(0.007)$ & $0.85(0.004)$ & $<0.0001$ \\
\hline
\end{tabular}


BMI, $\mathrm{kg} / \mathrm{m}^{2}$

Waist height ratio

Total percent fat, \%

Body lean mass, kg

BMD, $\mathbf{g} / \mathrm{cm}^{2}$

Appendicular skeletal muscle mass, $\mathrm{g}$
Waist circumference, $\mathrm{cm}$

Body fat mass, kg

\begin{tabular}{cccr}
$27.0(0.3)$ & $26.3(0.17)$ & $26.9(0.1)$ & 0.08 \\
$90.9(0.7)$ & $89.7(0.43)$ & $92.6(0.3)$ & $<0.0001$ \\
$0.55(0.004)$ & $0.54(0.003)$ & $0.54(0.002)$ & 0.19 \\
$33.4(0.4)$ & $33.8(0.3)$ & $30.6(0.2)$ & $<0.0001$ \\
$45.7(0.5)$ & $45.3(0.3)$ & $51.0(0.2)$ & $<0.0001$ \\
$24.7(0.4)$ & $24.9(0.3)$ & $24.1(0.2)$ & 0.02 \\
$1.13(0.006)$ & $1.13(0.004)$ & $1.16(0.003)$ & $<0.0001$ \\
$20.17(0.27)$ & $19.68(0.16)$ & $22.8(0.09)$ & $<0.0001$ \\
$7.31(0.08)$ & $7.04(0.05)$ & $7.70(0.03)$ & $<0.0001$ \\
\hline
\end{tabular}

Abbreviations: BMI, body mass index; BP, blood pressure; SMI, skeletal muscle index; BMD: body mineral density. Means and SEs were calculated for variables with normal distribution; and medians (ranges) were calculated for age. No. (\%) were calculated for categorical variables. 
Table 2. Associations between dietary sodium intake and obesity

\begin{tabular}{|c|c|c|c|c|c|}
\hline Sodium intake & $\begin{array}{c}\text { No. of obese/ } \\
\text { No. of Participants }\end{array}$ & $\begin{array}{l}\text { Model } 1 \text { ORs } \\
(95 \% \text { CIs }) *\end{array}$ & $\begin{array}{l}P \text {-values } \\
\text { for trend }\end{array}$ & $\begin{array}{l}\text { Model } 2 \text { ORs } \\
\text { (95\% CIs) }\end{array}$ & $\begin{array}{l}P \text {-values } \\
\text { for trend }\end{array}$ \\
\hline \multicolumn{6}{|l|}{ All participants } \\
\hline per $1 \mathrm{~g}$ & $2205 / 9162$ & $1.05(1.00,1.01)$ & & $1.15(1.00,1.33)$ & \\
\hline$<1500 \mathrm{mg} / \mathrm{d}$ & $209 / 805$ & $1.12(0.84,1.49)$ & 0.33 & $0.95(0.48,1.89)$ & 0.01 \\
\hline $1500-2300 \mathrm{mg} / \mathrm{d}$ & $420 / 1680$ & 1 & & 1 & \\
\hline$>2300 \mathrm{mg} / \mathrm{d}$ & $1576 / 6677$ & $1.12(0.97,1.29)$ & & $1.55(1.09,2.20)$ & \\
\hline \multicolumn{6}{|l|}{ Women } \\
\hline per $1 \mathrm{~g}$ & $1200 / 4349$ & $1.02(0.96,1.09)$ & & $1.31(1.02,1.69)$ & \\
\hline$<1500 \mathrm{mg} / \mathrm{d}$ & $155 / 490$ & $1.28(0.90,1.84)$ & 0.9 & $1.21(0.55,2.67)$ & 0.17 \\
\hline $1500-2300 \mathrm{mg} / \mathrm{d}$ & $297 / 1060$ & 1 & & 1 & \\
\hline$>2300 \mathrm{mg} / \mathrm{d}$ & $748 / 2799$ & $1.10(0.88,1.37)$ & & $1.63(1.06,2.50)$ & \\
\hline \multicolumn{6}{|l|}{ Men } \\
\hline per $1 \mathrm{~g}$ & $1005 / 4813$ & $1.06(1.01,1.11)$ & & $1.02(0.87,1.21)$ & \\
\hline$<1500 \mathrm{mg} / \mathrm{d}$ & $54 / 315$ & $0.79(0.50,1.26)$ & 0.21 & $0.44(0.12,1.56)$ & 0.11 \\
\hline $1500-2300 \mathrm{mg} / \mathrm{d}$ & $123 / 620$ & 1 & & 1 & \\
\hline$>2300 \mathrm{mg} / \mathrm{d}$ & $828 / 3878$ & $1.10(0.81,1.48)$ & & $1.12(0.58,2.16)$ & \\
\hline \multicolumn{6}{|l|}{ Non-Hispanic Black } \\
\hline per $1 \mathrm{~g}$ & $607 / 2012$ & $0.98(0.90,1.01)$ & & $0.98(0.76,1.25)$ & \\
\hline$<1500 \mathrm{mg} / \mathrm{d}$ & $64 / 198$ & $0.97(0.63,1.49)$ & 0.42 & $0.88(0.40,1.92)$ & 0.64 \\
\hline $1500-2300 \mathrm{mg} / \mathrm{d}$ & $135 / 383$ & 1 & & 1 & \\
\hline$>2300 \mathrm{mg} / \mathrm{d}$ & $408 / 1431$ & $0.89(0.66,1.19)$ & & $0.80(0.39,1.61)$ & \\
\hline \multicolumn{6}{|l|}{ Non-Hispanic White } \\
\hline per $1 \mathrm{~g}$ & $794 / 3778$ & $1.07(1.02,1.13)$ & & $1.23(1.02,1.49)$ & \\
\hline$<1500 \mathrm{mg} / \mathrm{d}$ & $43 / 215$ & $0.97(0.60,1.55)$ & 0.14 & $0.60(0.15,2.46)$ & 0.01 \\
\hline $1500-2300 \mathrm{mg} / \mathrm{d}$ & $125 / 620$ & 1 & & 1 & \\
\hline$>2300 \mathrm{mg} / \mathrm{d}$ & $626 / 2943$ & $1.14(0.92,1.40)$ & & $1.70(0.92,3.15)$ & \\
\hline \multicolumn{6}{|l|}{ Mexican American } \\
\hline per $1 \mathrm{~g}$ & $640 / 2577$ & $1.05(0.97,1.13)$ & & $1.21(0.95,1.54)$ & \\
\hline$<1500 \mathrm{mg} / \mathrm{d}$ & $78 / 311$ & $1.16(0.77,1.73)$ & 0.04 & $1.42(0.44,4.63)$ & 0.02 \\
\hline $1500-2300 \mathrm{mg} / \mathrm{d}$ & $128 / 527$ & 1 & & 1 & \\
\hline$>2300 \mathrm{mg} / \mathrm{d}$ & $434 / 1739$ & $1.50(1.24,1.81)$ & & $2.83(1.30,6.16)$ & \\
\hline \multicolumn{6}{|l|}{ Others } \\
\hline per $1 \mathrm{~g}$ & $164 / 795$ & $0.97(0.85,1.12)$ & & $0.96(0.64,1.43)$ & \\
\hline$<1500 \mathrm{mg} / \mathrm{d}$ & $24 / 81$ & $1.83(0.87,3.85)$ & 0.08 & $2.79(0.48,16.24)$ & 0.73 \\
\hline $1500-2300 \mathrm{mg} / \mathrm{d}$ & $32 / 150$ & 1 & & 1 & \\
\hline$>2300 \mathrm{mg} / \mathrm{d}$ & $108 / 564$ & $0.95(0.60,1.50)$ & & $1.30(0.43,3.96)$ & \\
\hline
\end{tabular}


by $\mathrm{BMI} \geqslant 30.0 \mathrm{~kg} / \mathrm{m}^{2}$. 
Table 3. Association between dietary sodium intake and central obesity

\begin{tabular}{|c|c|c|c|c|c|}
\hline Sodium intake & $\begin{array}{l}\text { No. of obese/ } \\
\text { No. of Participants }\end{array}$ & $\begin{array}{l}\text { Model } 1 \text { ORs } \\
(95 \% \text { CIs) }\end{array}$ & $\begin{array}{l}P \text {-values } \\
\text { for trend }\end{array}$ & $\begin{array}{l}\text { Model } 2 \text { ORs } \\
(95 \% \text { CIs) }\end{array}$ & $\begin{array}{l}P \text {-values } \\
\text { for trend }\end{array}$ \\
\hline \multicolumn{6}{|l|}{ All participants } \\
\hline per $1 \mathrm{~g}$ & $3274 / 9306$ & $1.07(1.03,1.12)$ & & $1.24(1.11,1.39)$ & \\
\hline$<1500 \mathrm{mg} / \mathrm{d}$ & $322 / 829$ & $1.22(0.96,1.57)$ & 0.03 & $1.28(0.72,2.29)$ & 0.003 \\
\hline $1500-2300 \mathrm{mg} / \mathrm{d}$ & $640 / 1714$ & 1 & & 1 & \\
\hline$>2300 \mathrm{mg} / \mathrm{d}$ & $2312 / 6763$ & $1.28(1.10,1.50)$ & & $1.78(1.29,2.45)$ & \\
\hline \multicolumn{6}{|l|}{ Women } \\
\hline per $1 \mathrm{~g}$ & $2052 / 4412$ & $1.07(1.01,1.14)$ & & $1.51(1.22,1.87)$ & \\
\hline$<1500 \mathrm{mg} / \mathrm{d}$ & $247 / 507$ & $1.26(0.92,1.72)$ & 0.08 & $1.47(0.75,2.88)$ & 0.08 \\
\hline $1500-2300 \mathrm{mg} / \mathrm{d}$ & $492 / 1079$ & 1 & & 1 & \\
\hline$>2300 \mathrm{mg} / \mathrm{d}$ & $1313 / 2826$ & $1.29(1.04,1.59)$ & & $1.75(1.14,2.70)$ & \\
\hline \multicolumn{6}{|l|}{ Men } \\
\hline per $1 \mathrm{~g}$ & $1222 / 4894$ & $1.06(1.01,1.12)$ & & $1.05(0.92,1.21)$ & \\
\hline$<1500 \mathrm{mg} / \mathrm{d}$ & $75 / 322$ & $1.07(0.66,1.76)$ & 0.27 & $0.81(0.24,2.70)$ & 0.06 \\
\hline $1500-2300 \mathrm{mg} / \mathrm{d}$ & $148 / 635$ & 1 & & 1 & \\
\hline$>2300 \mathrm{mg} / \mathrm{d}$ & $999 / 3937$ & $1.21(0.86,1.69)$ & & $1.45(0.74,2.83)$ & \\
\hline \multicolumn{6}{|l|}{ Non-Hispanic Black } \\
\hline per $1 \mathrm{~g}$ & $715 / 1452$ & $1.01(0.94,1.09)$ & & $0.98(0.77,1.24)$ & \\
\hline$<1500 \mathrm{mg} / \mathrm{d}$ & $81 / 205$ & $0.95(0.63,1.44)$ & 0.54 & $1.37(0.61,3.05)$ & 0.25 \\
\hline $1500-2300 \mathrm{mg} / \mathrm{d}$ & $157 / 393$ & 1 & & 1 & \\
\hline$>2300 \mathrm{mg} / \mathrm{d}$ & $477 / 1452$ & $1.06(0.78,1.43)$ & & $0.85(0.44,1.62)$ & \\
\hline \multicolumn{6}{|l|}{ Non-Hispanic White } \\
\hline per $1 \mathrm{~g}$ & $1347 / 3831$ & $1.08(1.02,1.13)$ & & $1.34(1.14,1.58)$ & \\
\hline$<1500 \mathrm{mg} / \mathrm{d}$ & $80 / 221$ & $1.13(0.78,1.63)$ & 0.02 & $1.33(0.58,3.05)$ & 0.001 \\
\hline $1500-2300 \mathrm{mg} / \mathrm{d}$ & $229 / 639$ & 1 & & 1 & \\
\hline$>2300 \mathrm{mg} / \mathrm{d}$ & $1038 / 2971$ & $1.33(1.08,1.64)$ & & $2.31(1.36,3.91)$ & \\
\hline \multicolumn{6}{|l|}{ Mexican American } \\
\hline per $1 \mathrm{~g}$ & $956 / 2613$ & $1.05(0.97,1.14)$ & & $1.03(0.83,1.28)$ & \\
\hline$<1500 \mathrm{mg} / \mathrm{d}$ & $121 / 319$ & $0.96(0.65,1.41)$ & 0.01 & $0.56(0.22,1.44)$ & 0.08 \\
\hline $1500-2300 \mathrm{mg} / \mathrm{d}$ & $205 / 531$ & 1 & & 1 & \\
\hline$>2300 \mathrm{mg} / \mathrm{d}$ & $630 / 1763$ & $1.33(1.04,1.71)$ & & $1.39(0.67,2.90)$ & \\
\hline \multicolumn{6}{|l|}{ Others } \\
\hline per $1 \mathrm{~g}$ & $256 / 577$ & $1.06(0.94,1.20)$ & & $1.07(0.80,1.44)$ & \\
\hline$<1500 \mathrm{mg} / \mathrm{d}$ & $40 / 84$ & $2.06(1.03,4.11)$ & 0.19 & $2.26(0.49,10.52)$ & 0.70 \\
\hline $1500-2300 \mathrm{mg} / \mathrm{d}$ & $49 / 577$ & 1 & & 1 & \\
\hline$>2300 \mathrm{mg} / \mathrm{d}$ & $167 / 577$ & $1.09(0.72,1.66)$ & 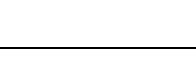 & $1.09(0.37,3.18)$ & \\
\hline
\end{tabular}


defined by waist circumference $>88 \mathrm{~cm}$ for women and $>120 \mathrm{~cm}$ for men. 
Table 4. Associations between dietary sodium intake adjusted by total energy intake and obesity

\begin{tabular}{|c|c|c|c|c|c|}
\hline Sodium intake & $\begin{array}{c}\text { No. of obese/ } \\
\text { No. of Participants }\end{array}$ & $\begin{array}{l}\text { Model } 1 \text { ORs } \\
\text { (95\% CIs) }\end{array}$ & $\begin{array}{l}P \text {-values } \\
\text { for trend }\end{array}$ & $\begin{array}{l}\text { Model } 2 \text { ORs } \\
(95 \% \text { CIs) }\end{array}$ & $\begin{array}{l}P \text {-values } \\
\text { for trend }\end{array}$ \\
\hline \multicolumn{6}{|l|}{ Obesity } \\
\hline per $1 \mathrm{~g}$ & $2205 / 9162$ & $1.11(1.05,1.18)$ & & $1.16(1.00,1.33)$ & \\
\hline Tertile 1 & $662 / 3023$ & $1.14(0.97,1.34)$ & 0.0008 & $1.11(0.78,1.59)$ & 0.09 \\
\hline Tertile 2 & $782 / 3016$ & 1 & & 1 & \\
\hline Tertile 3 & $761 / 3123$ & $1.25(1.10,1.42)$ & & $1.35(0.95,1.92)$ & \\
\hline \multicolumn{6}{|l|}{ Central obesity } \\
\hline per $1 \mathrm{~g}$ & $3274 / 9306$ & $1.13(1.07,1.19)$ & & $1.25(1.12,1.39)$ & \\
\hline Tertile 1 & $981 / 3071$ & $1.09(0.94,1.26)$ & $<0.0001$ & $1.42(1.02,1.96)$ & 0.005 \\
\hline Tertile 2 & $1152 / 3070$ & 1 & & 1 & \\
\hline Tertile 3 & $1141 / 3165$ & $1.29(1.15,1.44)$ & & $1.59(1.18,2.15)$ & \\
\hline
\end{tabular}

* The ORs and 95\% CIs were calculated after adjustment for age, gender, and ethnicity;

** The ORs and 95\% CIs were calculated after adjustment for age, gender, race, smoking, alcohol drinking, physical activity, education, family annual income, and total energy intake.

Dietary sodium intake is adjusted by total energy intake by using residual method.

Central obesity is defined by BMI $\geqslant 30.0 \mathrm{~kg} / \mathrm{m}^{2}$ and central obesity defined by waist circumference $>88$ $\mathrm{cm}$ for women and $>120 \mathrm{~cm}$ for men. 
Table 5. Associations (Regression coefficients [95\% CIs]) between dietary sodium intake and body composition

\begin{tabular}{|c|c|c|}
\hline \multirow{2}{*}{ Body compositions } & \multicolumn{2}{|c|}{ Regression coefficients ( $95 \%$ CIs) for body compositions } \\
\hline & Dietary sodium intake, per $\mathbf{g} / \mathrm{d}$ & Dietary sodium density, per $\mathrm{mg} / \mathrm{kcal}$ \\
\hline Total percent fat, $\%$ & $0.44(0.07,0.81)$ & $1.09(0.28,1.90)$ \\
\hline Body lean mass, kg & $0.53(0.14,0.92)$ & $1.22(0.43,2.01)$ \\
\hline Body fat mass, $\mathrm{kg}$ & $0.79(0.17,1.40)$ & $1.96(0.69,3.19)$ \\
\hline ASM, kg & $0.32(0.07,0.57)$ & $0.72(0.20,1.23)$ \\
\hline ASMI, $\mathrm{kg} / \mathrm{m}^{2}$ & $0.10(0.03,0.17)$ & $0.24(0.09,0.39)$ \\
\hline Weight, kg & $1.38(0.14,2.62)$ & $3.37(0.89,5.84)$ \\
\hline BMI, $\mathrm{kg} / \mathrm{m}^{2}$ & $0.50(0.09,0.91)$ & $1.28(0.45,2.10)$ \\
\hline Waist, cm & $1.07(0.28,1.85)$ & $2.63(1.18,4.09)$ \\
\hline
\end{tabular}

Regression coefficients (95\% CIs) were calculated by using the linear regression model. 


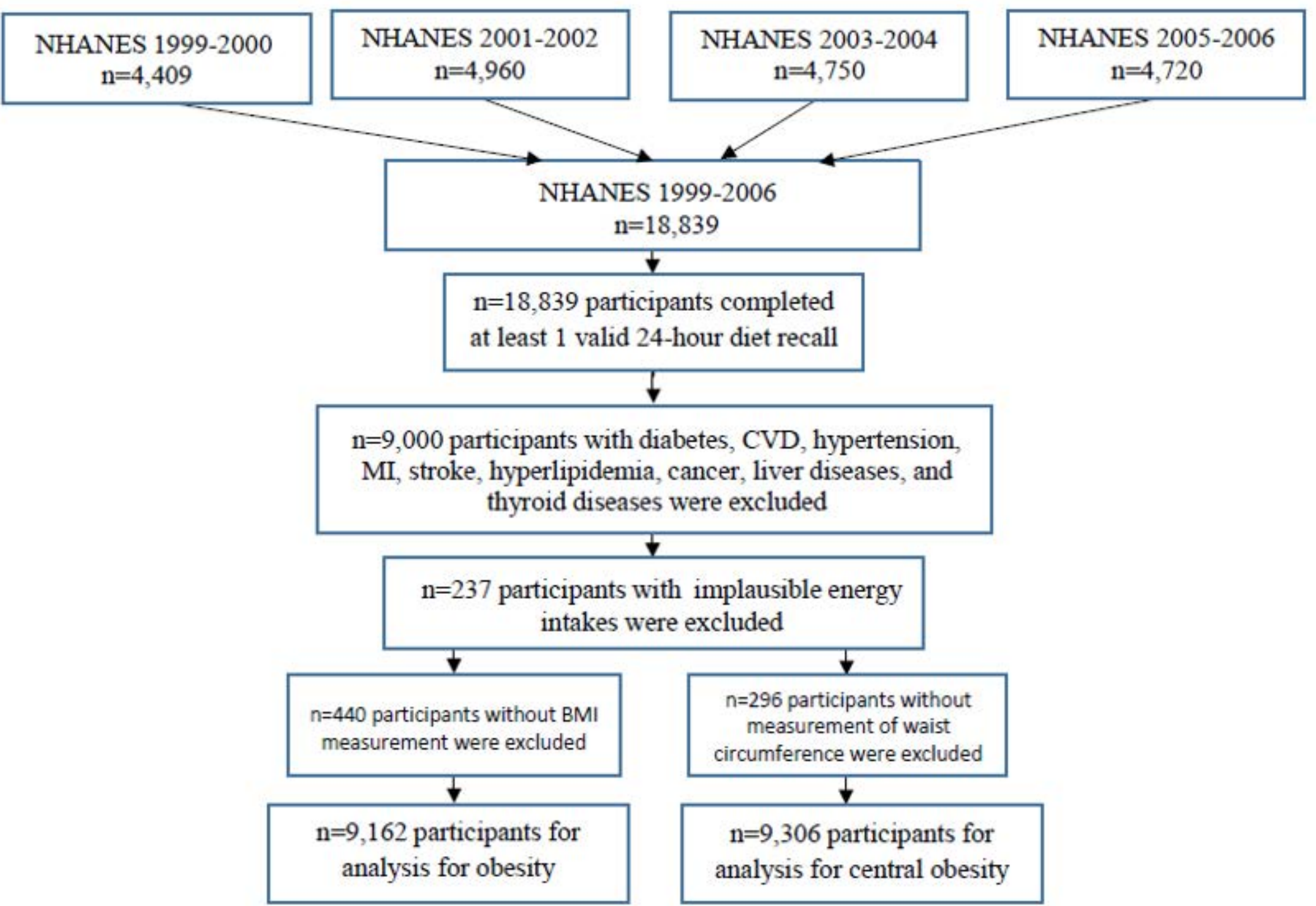




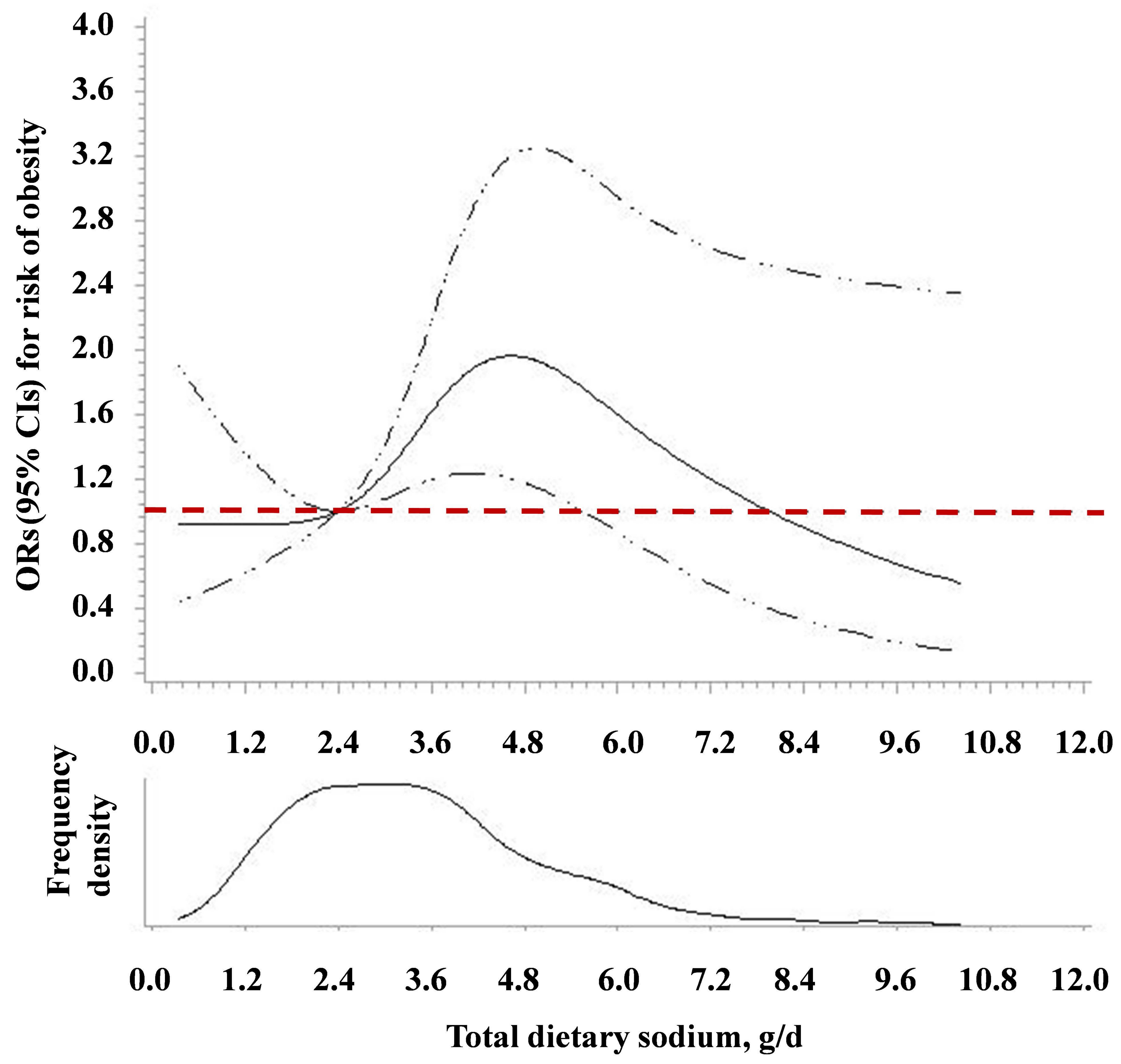



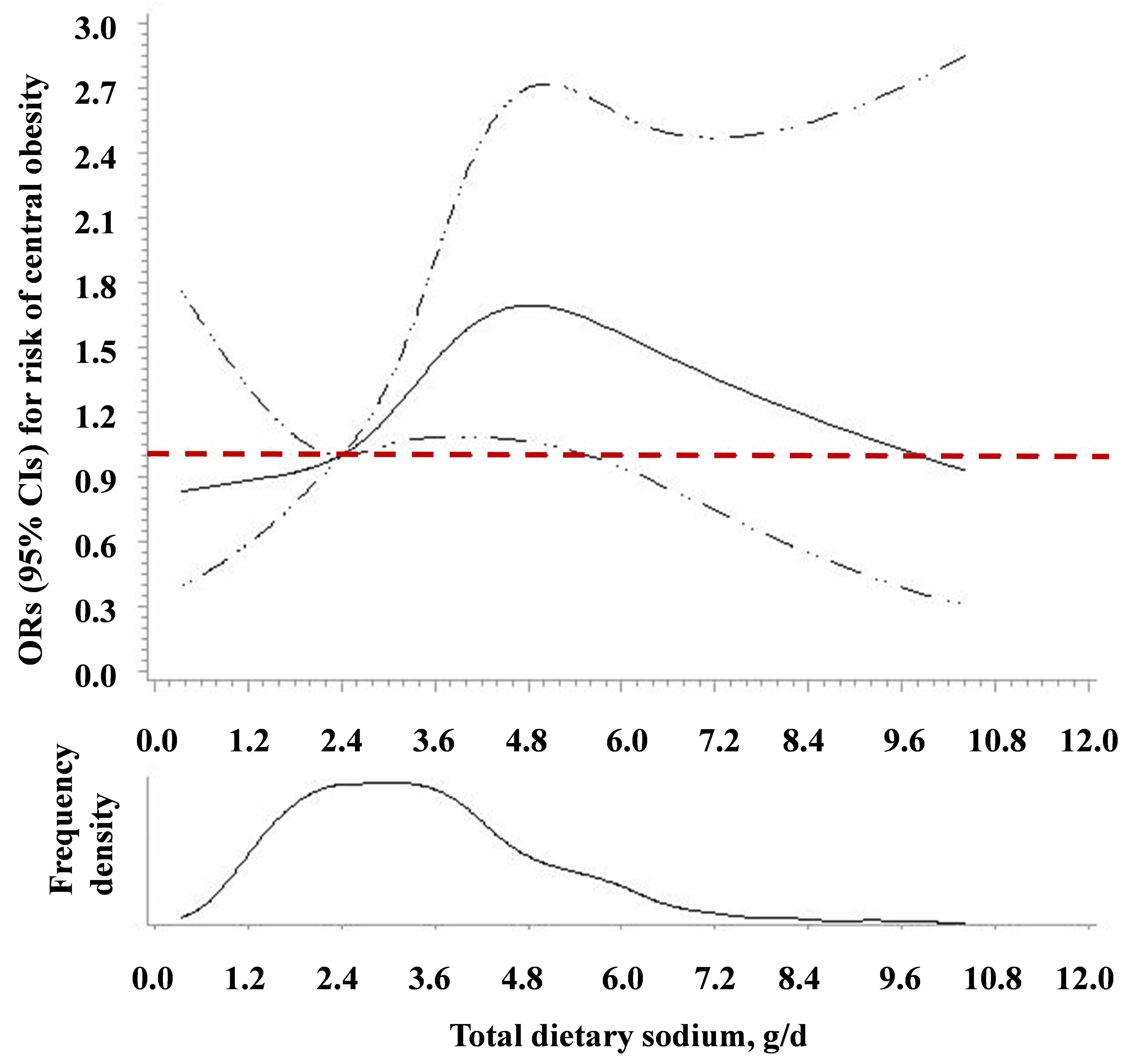
Quartiles for dietary sodium density, mg/kcal

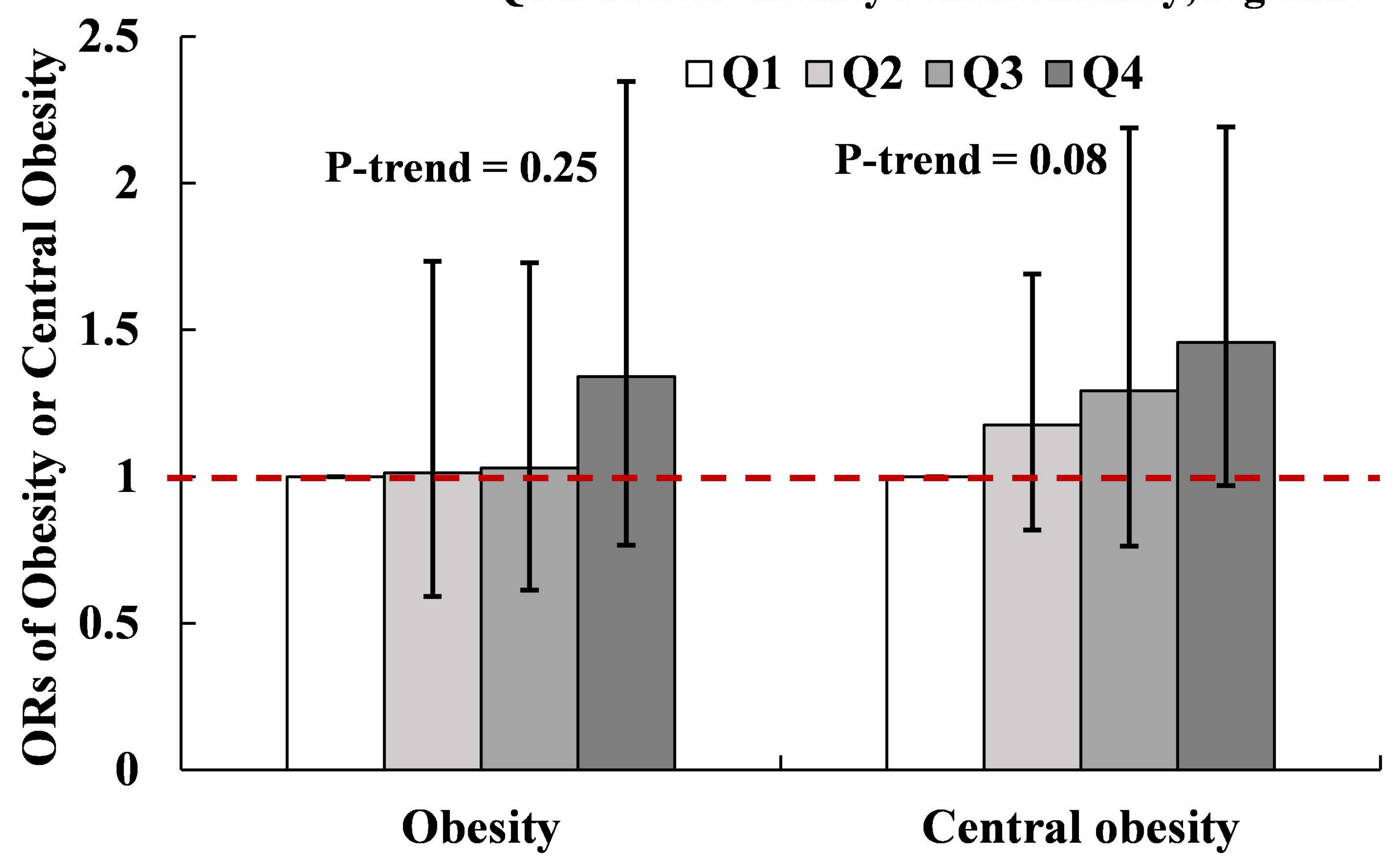

